\title{
Overweight, obesity, high blood pressure and lifestyle factors among Mexican children and their parents
}

\author{
Arely Vergara-Castañeda $\cdot$ Lilia Castillo-Martínez • \\ Eloisa Colín-Ramírez $\cdot$ Arturo Orea-Tejeda
}

Received: 16 February 2010/ Accepted: 22 April 2010/Published online: 15 May 2010

(C) The Japanese Society for Hygiene 2010

\begin{abstract}
Objective The objective of this study was to identify associations in the prevalence of overweight, obesity and high blood pressure between children and their parents, as well as their eating and physical patterns.

Methods In this cross-sectional study, we obtained data on 83 pairs of school-aged children and one of their parents relating to dietary habits and various physical parameters, including the body mass index (BMI) and blood pressure of the children, which were adjusted by age and gender. Both the children and the parents were asked to complete a questionnaire aimed at providing measures of eating behavior. The questions focused on the consumption of fruit and vegetables and soda drinks as well as on physical activity patterns. Parent BMI was calculated from selfreported height and weight values.

Results Obesity was diagnosed in $10.8 \%$ of the children, and the prevalence of overweight was $28.9 \%$. There was a relationship between a child's weight status and that of his/ her parent according to the BMI; $45 \%$ of overweight/obese children had overweight/obese parents. In addition, a parent's fruit and vegetable consumption was associated with his/her child's fruit and vegetable consumption $(r=0.47$, $p<0.001)$, and both were associated with soda drink
\end{abstract}

L. Castillo-Martínez ( $₫) \cdot$ E. Colín-Ramírez · A. Orea-Tejeda Heart Failure Clinic, Instituto Nacional de Ciencias Médicas y Nutrición "Salvador Zubirán",

Providencia 1218-A 402 Col. del Valle, CP 03100 Benito Juárez, Mexico City, Mexico e-mail: caml1225@yahoo.com

A. Vergara-Castañeda $\cdot$ L. Castillo-Martínez .

E. Colín-Ramírez · A. Orea-Tejeda

Asociación Mexicana para la Prevención de Insuficiencia

Cardiaca AC, Mexico City, Mexico consumption in both parents and children $(r=0.30$, $p<0.001$ ).

Conclusion Our results confirmed that there is a relationship between the weight status, fruit and vegetable consumption and soda drink intake of children and those of their parents.

Keywords Children - Eating and physical patterns . Obesity · Parental influence

\section{Introduction}

Overweight and obesity affects $26 \%$ of Mexican school children and the prevalence has continued to increase in recent years [1]. Childhood overweight and obesity are associated with a wide range of immediate health concerns, such as the development of insulin resistance, type 2 diabetes mellitus [2,3] dyslipidemia, hypertension, and with an increasing the risk of disease in adulthood $[4,5]$. The results of one study showed that after 6 years of age, the probability of obesity in adulthood exceeded 50\% for obese children compared with about $10 \%$ for non-obese children [6].

While there are many factors related to this increasing trend towards overweight and obesity, energy imbalance linked with a shift in energy sources and total energy intake and physical activity are the most important $[7,8]$. The increased risk of childhood overweight has been associated with the increased frequency of inactive leisure time pursuits, such as watching television and using the computer $[9,10]$.

The increased consumption of sugar-sweetened beverages is also associated with a higher energy intake, weight gain, obesity and diabetes [11-13]. Current estimations are 
that sugary drinks contribute $8-9 \%$ of the total energy intake in both children and adults [14], with $4 \%$ coming from the consumption of soda drinks [15]. In contrast, $2 \%$ of the total energy intake in Mexican families come from fruit and vegetable consumption. It has been reported that $10.6 \%$ of the family income is designated to buying beverages whereas $16.4 \%$ is used to purchase for fruits, vegetables, legumes and seeds [16].

Data from industrial sources indicates that Mexico is the second largest consumer of soda drinks in the world [17], and this consumption alone may be an important contributory factor to the unprecedented increase in obesity [18]. In Mexico, the percentage of households consuming soda drinks rose from 48 to $60 \%$ between 1989 and 2006. The percentage of overall daily energy intake from energycontaining beverages in Mexican adolescents and adults $(22.5 \%)$ was higher than that in a nationally representative survey of the U.S. population (21\%) [19].

The role of the home environment in the development of childhood overweight and obesity has been recognized for a long time, and parental obesity is believed to increase the risk of adult obesity in children [20, 21]. Some studies originating in Europe and North America support the findings that the degree of tracking of weight status from childhood to early and mid-adulthood is related with parental weight status, suggesting that the body mass index (BMI) of sons are significantly correlated with those of both their mothers and fathers at every age $[6,22]$. There have also been reports suggesting that the risk of becoming obese in young adulthood is three- to fivefold higher if either the mother or father is obese compared with the parent not being obese [6, 20, 23]. However, other findings suggest that parental behaviors shape many aspects of a child's development; as such, a parent's diet history and eating habits would influence the development of children's eating behaviors and weight outcomes [24, 25].

Family, friends, school and media also influence children's eating behavior [26]. Healthier choices at one stage in life are associated with healthier choices at a later stage $[27,28]$ because habits acquired in childhood are critical to the acquisition of healthy habits [27] and prevention of sedentary behavior [29]. However, there is as yet comparatively little evidence that dietary habits persist into adult life, principally because there have been very few longitudinal studies. In particular, few investigations have included hypertension in children and parent's eating and physical behavior in their study design [30].

To clarify the relationship between parental eating patterns and those of children and also to consider cardiovascular risk factors, we studied 83 pairs of children and one of each child's parents for associations in the prevalence of overweight, obesity and high blood pressure. We also analyzed the relationship between the parent's physical activity patterns and those of the child.

\section{Methods}

Subjects

This cross-sectional descriptive study included 83 pairs of children and one of their respective parents from a convenience sample of children attending one of five public schools in an area of low socioeconomic status in Mexico City; the schools were located in five districts: Tlalpan, Xochimilco, Coyoacán, Benito Juaréz and Álvaro Obregón. To guarantee the homogeneity of the sample, we recruited all children from public schools considered to be marginalized, based on an index which groups nine indicators of social exclusion, revealing the relative disadvantages that faces a population as result of its geographic, economic and social situation [31].

Participating schools were selected randomly by the Secretaría de Educación Pública in an approach ensuring that the sample was proportionally selected for each area. All fifth- and sixth-grade students enrolled in the five elementary schools were invited to participate in the study, and their parents were asked to attend a meeting in their children's school where they received information on the study; the children of parents who provided written informed consent were recruited.

The study is in accordance with the ethical standards of the Ethics and Investigation in Humans Committee of the Secretaría de Salud del Gobierno del Distrito Federal, a federal institution who approved the entire study to ensure the protection of all the participants. Children were included only if they and their parents signed a written and informed consent form before all measurements were made. In addition, parents were also asked to sign a personal consent form when completing the questionnaires, which is in accordance with the Helsinki Declaration.

\section{Measurements}

Anthropometric, blood pressure (BP), physical activity and dietary patterns evaluations were performed on all children. All data were collected in the morning immediately after the children arrived at school.

Anthropometric data on the children were collected by a group of trained nutritionists during the first hours of classes. Weight (SECA professional scale model 750; Seca North America, Hanover, MD) and height (SECA model 280 portable stadiometer; Seca North America) were measured in accordance to the reference manual of anthropometric standardization [32]. All measurements 
were taken with shoes and heavy outer clothing removed. The BMI was calculated by dividing the total body weight $(\mathrm{kg})$ by the squared height $\left(\mathrm{m}^{2}\right)$ and then making adjustments for age and gender according to the National Health and Nutrition Examination Survey (NHANES) I [33]. Obesity was defined as a BMI $>95$ th percentile for age and gender, and children were considered to be at risk of obesity if the BMI $\geq 85$ th and $<95$ th percentile, which is in agreement with the international obesity task force (IOFT) cut-off points [34]. The BMI of the children was categorized into group: "underweight/normal" versus "at risk for overweight/overweight".

Blood pressure evaluations were performed in all children according to the standardized technique described by the American Heart Association (AHA) [35]: levels were measured in the right arm, with the child in the seated position, by auscultation and mercury sphygmomanometer using the appropriate cuff size. The first Korotkoff sound was used to determine the systolic BP (SBP) level, and the fifth Korotkoff sound was used to determine the diastolic BP (DBP). High blood pressure (HBP) was classified as SBP or $\mathrm{DBP} \geq 95$ th percentile for age, gender and height of children without taking pre-hypertension into consideration.

Parents were assessed with a self-administered survey at their children's school under the guidance of a trained research assistant. Completion of the questionnaire took $30 \mathrm{~min}$ and included questions on age, gender, parental marital status and occupation. The parents were also asked to report their actual weight and height. Previous studies in adults have reported correlations between actual and reported height and weights that typically range between 0.96 and 0.99 [36, 37]. Parental BMI was categorized as underweight (BMI <18.5), normal (BMI 18.5-24.9), overweight (BMI $\geq 25)$ and obesity (BMI $\geq 30$ ).

Another section of the parent's questionnaire focused on the presence of cardiovascular risk factors, such as diabetes, hypercholesterolemia, stroke or any cardiovascular disease, HBP or hypertension and the use of medications to control these diseases.

Diet patterns were assessed with a questionnaire that focused on the intake of fruit, vegetables and soda drinks and was completed by both parents and children. For the children, we used the Spanish version of The School Physical Activity and Nutrition questionnaire (SPAN), which had been tested previously for validity and reliability in a Hispanic population [38]. For the parents, there was a special section on their questionnaire that focused on the same eating behaviors.

Both groups (children and parents) were assisted in completing the questionnaire by a trained nutritionist who also gave an explanatory lecture about the questionnaire and verified that the participants understood the items. The SPAN includes six questions, such as "Yesterday, did you eat vegetables? Vegetables include all kinds, raw or cooked, and salads. Don't consider potatoes cooked or fried". "Yesterday, did you eat fruit? Don't consider fruit juice"; the response categories for such items included $1=$ yes, $2=$ no. For questions focusing on consumption portions, such as "Yesterday, how many times did you eat fruit? Don't consider fruit juice", "Yesterday did you drink any soda drink of sweetened beverages? (Not diet ones)", the response categories for each item included $0=$ no, I didn't drink any soda drinks, $1=$ yes, I drank one soda drink or sweetened beverage (not diet), 2 = yes, I drank two soda drinks or sweetened beverages (not diet) and $3=$ yes, I drank three or more soda drinks or sweetened beverages (not diet). Parents were asked about their diet patterns using eight questions, such as "How many glasses of soda drink do you drink during a day?" ( 1 glass is equal a $240 \mathrm{ml}$ ); response categories include $0=$ any glass, $1=1$ glass, $2=2$ glasses, $3=\geq 3$ glasses and $4=$ Don't know or don't remember.

Assessments of physical activity behavior included recording the usual physical activity patterns of the children by assessing light and moderate physical activity and leisure activities, such as watching TV, using the computer and playing videogames. Eight questions in the SPAN included, "Yesterday, how many hours did you watch TV or video games away from school?", "How many hours per day do you usually spend on the computer away from school?"; response categories for each item included $1=$ none, $2=1-3 \mathrm{~h}$ and $3=>3 \mathrm{~h}$. Information on moderate to vigorous physical activity was obtained by asking, "In the last week, how many days did you exercise or participate in an activity that made your heart beat fast and made you breathe hard, for at least for $20 \mathrm{~min}$ (for example: basketball, jogging, skating, fast dancing, swimming laps, tennis, fast bicycling, or aerobics)?"; response categories for each item included $1=1-3$ days and $2=$ more than 3 days.

Parental physical patterns were assessed using The Rapid Assessment Physical Activity Scale (RAPA). This scale involves nine yes/no items assessing the type and amount of physical activity in which adults engage [39]. The major advantage of using the RAPA is that it is a quick and easy scoring sheet, available in different languages, which enables respondents to visualize differences between activity intensity.

\section{Statistical analysis}

All statistics were performed with commercially available software (SPSS ver. 12.0 for Windows, 2003; SPSS, Chicago, IL) Continuous variables are given as means \pm standard deviation (SD), and categorical variables are presented as absolute and relative frequencies. Descriptive 
statistics are presented by gender. Spearman's correlation coefficients were calculated to assess the association between child weight and BP status variables and potential parent-associated factors (parental BMI, presence of cardiovascular risk factors, eating and physical patterns). To identify the parental factors associated to obesity, children were divided into overweight/obese and normal classes, respectively. The Mann-Whitney test was used to compare groups. The results were considered to be statistically significant at $p<0.05$.

\section{Results}

A total of 83 pairs of children and their parents were included in the study; the mean age of the recruited children was $9.4 \pm 0.6$ years old, and $54 \%$ were male. Table 1 presents the descriptive characteristics of the children. The mean BMI of the children was $18.8 \pm 3.2 \mathrm{~kg} / \mathrm{m}^{2}$. Almost $11 \%(10.8 \%)$ were obese, with a mean BMI of $24.5 \mathrm{~kg} / \mathrm{m}^{2}$; of these obese children, $13.3 \%$ were boys. The proportion of children in the total sample assessed as at risk of obesity or as being overweight was $28.9 \%$, with a mean BMI of $21.2 \mathrm{~kg} / \mathrm{m}^{2}$; there were more males than females in this group (31.3 vs. $26.3 \%$, respectively). Mean SBP and DBP were $110.53 \pm 15.5$ and $74.1 \pm 15.8 \mathrm{mmHg}$, respectively. The prevalence of systolic and diastolic HBP in this group

Table 1 Descriptive characteristics of the Mexican school-aged children of low socioeconomic status in Mexico City according to gender

\begin{tabular}{|c|c|c|c|}
\hline Variables & $\begin{array}{l}\text { Total } \\
(n=83)\end{array}$ & $\begin{array}{l}\text { Male } \\
(n=45)\end{array}$ & $\begin{array}{l}\text { Female } \\
(n=38)\end{array}$ \\
\hline Age (years) & $9.4 \pm 0.6$ & $9.5 \pm 0.6$ & $9.4 \pm 0.6$ \\
\hline Weight (kg) & $34.8 \pm 7.9$ & $35.4 \pm 7.9$ & $34.1 \pm 7.9$ \\
\hline Height (cm) & $135.4 \pm 6.3$ & $135.5 \pm 5.3$ & $135.2 \pm 7.4$ \\
\hline BMI $\left(\mathrm{kg} / \mathrm{m}^{2}\right)$ & $18.8 \pm 3.2$ & $19.1 \pm 3.4$ & $18.4 \pm 2.9$ \\
\hline Systolic BP (mmHg) & $110.5 \pm 15.5$ & $111.8 \pm 16.5$ & $109.1 \pm 14.3$ \\
\hline Diastolic BP (mmHg) & $74.4 \pm 15.8$ & $77.6 \pm 16.1$ & $70.6 \pm 14.6$ \\
\hline Overweight $(\%)^{\mathrm{a}}$ & 28.9 & 31.3 & 26.3 \\
\hline Obese $(\%)^{\mathrm{b}}$ & 10.8 & 13.3 & 7.9 \\
\hline $\begin{array}{l}\text { Systolic hypertension } \\
(\%)\end{array}$ & 34.9 & 40.0 & 28.9 \\
\hline $\begin{array}{l}\text { Diastolic hypertension } \\
(\%)\end{array}$ & 39.8 & 44.4 & 34.2 \\
\hline Hypertension (\%) & 48.2 & 51.1 & 44.7 \\
\hline
\end{tabular}

$B M I$ body mass index, $B P$ blood pressure

Values are expressed as the mean \pm standard deviation (SD) or as a percentage, where appropriate

${ }^{\text {a }}$ Overweight was defined as a BMI $>85$ th percentile for age and gender

${ }^{\mathrm{b}}$ Obesity was defined as a BMI $>95$ th percentile for age and gender was elevated by 34.9 and $39.8 \%$, respectively, and was much higher in males than females (51.1 vs. $44.7 \%$, respectively).

In total, $62.2 \%$ of the children considered to have systolic hypertension belonged to the overweight/obese group $(p=0.003)$; in comparison, of those children who presented with diastolic hypertension, $54.5 \%$ were overweight or obese $(p=0.02)$ (data not shown).

Of the parents recruited, $90 \%$ were females, most respondants reported that they were married $(79 \%)$ and the most common occupation was working at home (43.9\%) (data not shown). The parent's cardiovascular risk factors are shown in Table 2. Based on the assessment of parental weight status (self-reported), $43.2 \%$ were overweight and $19.3 \%$ were obese. In addition, $94 \%$ of the parents reported not to have problems with their BP, while the prevalence reported for diabetes mellitus, cholesterol or cardiovascular disease was $9.2 \%$.

The results of the evaluation to determine whether there were relationships between the dietary habits of the children and their weight and BP status were inconclusive in terms of fruit and vegetable consumption. However, of those children who reported that they did not consume soda drink beverages, $71.1 \%$ were considered to fall in the normal weight group ( $p=0.51$ ), and $44.7 \%$ presented systolic or diastolic hypertension $(p=0.70)$. Among those children who reported performing regular moderate physical activities, only one out of four were considered to be overweight/ obese, and almost $42 \%$ presented HBP; however, these results were not statically significant $(p=0.23)$.

In terms of eating patterns in Table 3 , in general, the children had a low consumption of fruit and vegetables:

Table 2 Descriptive characteristics of the parents of Mexican school-aged of low socioeconomic status in Mexico City according to gender

\begin{tabular}{llll}
\hline Variables & $\begin{array}{l}\text { Total } \\
(n=83)\end{array}$ & $\begin{array}{l}\text { Male } \\
(n=8)\end{array}$ & $\begin{array}{l}\text { Female } \\
(n=75)\end{array}$ \\
\hline Age (years) & $38.7 \pm 8.8$ & $42.9 \pm 9.4$ & $37.7 \pm 8.4$ \\
Weight $(\mathrm{kg})$ & $68.2 \pm 11.2$ & $79.7 \pm 11.7$ & $65.8 \pm 9.7$ \\
Height $(\mathrm{cm})$ & $159.4 \pm 0.8$ & $170.9 \pm 7.9$ & $156.9 \pm 6.2$ \\
BMI $\left(\mathrm{kg} / \mathrm{m}^{2}\right)$ & $26.9 \pm 3.6$ & $27.4 \pm 3.3$ & $26.7 \pm 3.7$ \\
Overweight $(\%)^{\mathrm{a}}$ & 43.2 & 53.3 & 41.1 \\
Obese $(\%)^{\mathrm{b}}$ & 19.3 & 20.0 & 19.2 \\
Hypertension $(\%)$ & 6.1 & 0 & 7.3 \\
Cardiovascular risk $(\%)^{\mathrm{c}}$ & 9.2 & 11.1 & 6.1 \\
\hline
\end{tabular}

Values are expressed as the mean \pm SD or as a percentage, where appropriate

a Overweight was defined as a BMI $\geq 25.0$

b Obesity was defined as a $\mathrm{BMI} \geq 30.0$

c Cardiovascular risk including any hypertension, hypercholesterolemia and other cardiovascular diseases 
Table 3 Prevalence of cardiovascular risk factors, eating and physical patterns in school-aged children of low socioeconomic status in Mexico City according to parent's weight status

\begin{tabular}{|c|c|c|c|c|}
\hline \multirow[t]{2}{*}{ Children's variables } & \multicolumn{3}{|c|}{ Parent's variables } & \multirow[t]{2}{*}{$p$ value $^{a}$} \\
\hline & $\begin{array}{l}\text { Total } \\
(n=83)\end{array}$ & $\begin{array}{l}\text { Normal weight } \\
(n=31)\end{array}$ & $\begin{array}{l}\text { Overweight/obesity } \\
(n=52)\end{array}$ & \\
\hline Overweight and obesity (\%) & 41.2 & 35.7 & 45.0 & 0.46 \\
\hline Systolic HBP (\%) & 30.9 & 28.6 & 32.5 & 0.47 \\
\hline Diastolic HBP (\%) & 39.7 & 39.3 & 40.0 & 0.58 \\
\hline $\operatorname{HBP}(\%)^{\mathrm{b}}$ & 47.1 & 46.4 & 47.5 & 0.56 \\
\hline \multicolumn{5}{|l|}{ Eating patterns } \\
\hline F/V consumption, portions & $1.0 \pm 0.8$ & $1.23 \pm 0.9$ & $0.85 \pm 0.7$ & $0.09^{\mathrm{c}}$ \\
\hline F/V consumption $(\%)$ & 2.0 & 4.8 & 0 & 0.24 \\
\hline Soda drinks consumption, portions & $0.70 \pm 0.9$ & $0.47 \pm 0.6$ & $0.78 \pm 0.9$ & 0.20 \\
\hline Soda drinks consumption $(\%)$ & 10.2 & 4.8 & 14.3 & 0.28 \\
\hline \multicolumn{5}{|l|}{ Physical activity patterns } \\
\hline Moderate activity (h/week) & $3.7 \pm 2.5$ & $4.0 \pm 2.6$ & $3.6 \pm 2.5$ & 0.59 \\
\hline Moderate activity (\%) & 91.8 & 85.7 & 96.4 & 0.20 \\
\hline TV watching and videogames (h/day) & $4.6 \pm 3.2$ & $4.9 \pm 3.8$ & $4.9 \pm 4.3$ & 0.94 \\
\hline TV watching and videogames (\%) & 89.8 & 85.7 & 92.9 & 0.36 \\
\hline
\end{tabular}

Values are expressed as the mean $\pm \mathrm{SD}$, or as a percentage, where appropriate

$F / V$ fruit and vegetables, $H B P$ high blood pressure; classified according to height and gender percentiles

a Mann-Whitney $U$ test

b Including systolic or diastolic HBP

c Showing trend for increased number of portions of fruit consumed by children and parents with a normal weight

$1.0 \pm 0.82$ portions per day. Of the children who reported not to consume any fruit or vegetables, $100 \%$ presented the same behavior as their parents, who also did not consume fruit or vegetables $(p=0.20)$ (data not shown). The proportion of children who reported consuming fruit and vegetables was higher in those children whose parents were classified as have a normal weight status compared with those who were overweight/obese (4.8 vs. $0 \%$, respectively; $p=0.2$ ); The same trend was observed for the number of portions of fruit and vegetables consumed per day (1.23 vs. 0.85 portions per day, respectively; $p=0.09)$. With respect to the consumption of soda drinks, the mean number of glasses drunk by the parents and children was $2.49 \pm 1.13$ and $0.70 \pm 0.9$ glasses/day, respectively. The proportion of children and parents who were accustomed to drinking these kinds of beverages was 10.2 and $71.7 \%$, respectively.

In terms of physical activity patterns, most of the children $(91.8 \%)$ reported practicing some form of moderate physical activity for an average length of time of $3.7 \mathrm{~h} /$ week; in comparison, $89.8 \%$ of the children reported spending $4.6 \mathrm{~h} /$ day watching TV. Among the parents, $37.5 \%$ reported doing some form of moderate physical activity at least three times per week.

The proportion of overweight or obese children was higher among those whose parents were also overweight or

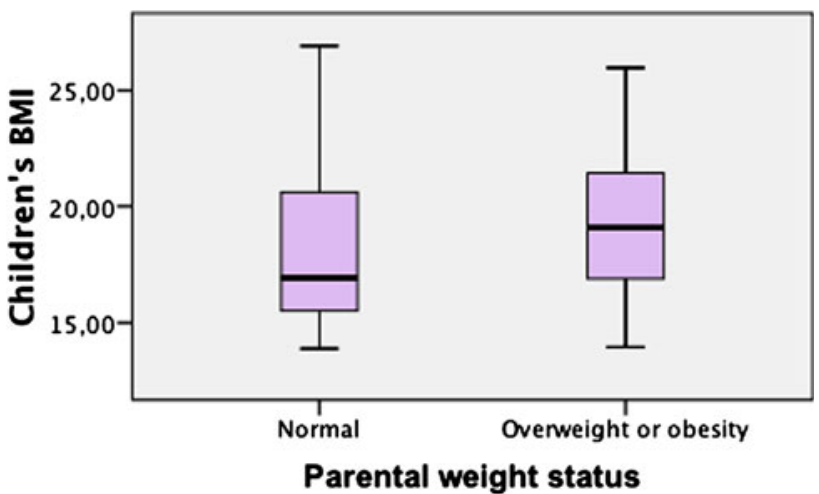

Fig. 1 The body mass index (BMI) of our cohort of Mexican schoolaged children according to weight status of the parents grouped according to BMI

obese versus those classified as having a normal weight status (45 vs. $35.7 \%$, respectively; $p=0.46$ ). Figure 1 presents the distribution of the children's BMI according to parental weight status; the median value for the children's BMI was higher if the father or mother was considered to be overweight or obese compared with those considered to have a normal weight (19.08 vs. $16.93 \mathrm{~kg} / \mathrm{m}^{2}$, respectively) even though there was no statistical difference for means between these groups (19.31 vs. $18.26 \mathrm{~kg} / \mathrm{m}^{2}$, respectively; $p=0.201)$. 
Table 4 Correlations between the diet and activity patterns of the parents and those of their children

\begin{tabular}{lccrr}
\hline Children's variables & \multicolumn{2}{l}{ Parent's variables } & & \\
\cline { 2 - 5 } & Overweight/obesity & F/V consumption & SD consumption & Moderate regular PA \\
\hline Overweight/obesity & $0.09(0.45)$ & $-0.048(0.67)$ & $0.02(0.85)$ & $-0.02(0.91)$ \\
HBP $^{\mathrm{a}}$ & $0.01(0.93)$ & $0.14(0.21)$ & $0.04(0.75)$ & $-0.10(0.49)$ \\
F/V consumption & $-0.33(0.06)$ & $0.47(<0.001)^{*}$ & $-0.25(0.88)$ & $0.27(0.21)$ \\
SD consumption & $0.151(0.40)$ & $0.30(<0.001)^{*}$ & $0.22(0.18)$ & $-0.12(0.59)$ \\
Light PA practice & $-0.18(0.31)$ & $0.17(0.28)$ & $0.31(0.65)$ & $0.11(0.60)$ \\
Moderate PA & $-0.21(0.23)$ & $0.09(0.55)$ & $-0.34(0.03)^{*}$ & $0.07(0.73)$ \\
Sedentary behavior & $-0.21(0.23)$ & $-0.11(0.52)$ & $0.28(0.89)$ & $0.05(0.87)$ \\
\hline
\end{tabular}

Values are presented as $r$, with the $p$ value in parenthesis

$P A$ Physical activity

$* p<0.05$

${ }^{\text {a }}$ Including systolic or diastolic HBP

${ }^{b}$ Watching TV $>4$ h/day

The results were not conclusive for the children in terms of intake of soda drinks, but a trend was identified; those whose parents presented with overweight/obesity consumed more portions of this kind of beverage ( 0.78 vs. 0.47 ; $p=0.20)$, and the proportion was higher (14.3 vs. 4.8, $p=0.28)$ compared with parents with a normal weight.

Table 4 shows the bivariate associations between the diet and activity patterns of the parents and those of their children. It can be seen that the fruit and vegetable consumption of the parents is associated with that of their children $(r=0.47, p<0.001)$, as is the consumption of soda drinks $(r=0.30, p<0.001)$. No significant results were found for physical activity.

\section{Discussion}

The prevalence of overweight and obesity among the children participating in this study, $37 \%$, is higher than that reported previously, $26.6 \%$, by the National Survey of Nutrition in Mexico in 2006. The pathogenesis of obesity suggests that environmental factors are implicated in the rapid increase in prevalence of childhood overweight and obesity that has occurred in the past years. One of these factors is a low socioeconomic level in developed countries [40], where the increasing of obesity has been related to increasing of poverty [41]. Our findings, based on schoolage children from a low socioeconomic population in Mexico City considered to be a high risk group, support this hypothesis.

Available data reveal sex differences in trends in the prevalence of overweight and obesity among school children, with girls showing a much more dramatic frequency in obesity than boys [42]. The greater prevalence of overweight and obesity in the boys of our sample is striking, but the use of a small sample limits the generalization of our findings. In terms of the greater number of cases of HBP found in our sample, both systolic and diastolic, it is important to realize that we used duplicated BP measures and that, in general, the prevalence of HBP decreases when more than two readings are taken during one visit (the first reading is ruled out and the last readings are averaged) and when subsequent visits are paid to an already reported case of pre- or hypertension [43, 44].

A significant correlation between the BMI of the parents and their children was found $(r=0.264, p=0.030)$, which is in agreement with the consistent correlations in subjects in a British study between both the mother and father and their children, although in the latter study the $r$ values ranged from 0.20 between fathers and sons to 0.49 between mothers and daughters [22]. In general, most of the reported correlation coefficients were around 0.35 [20].

One of the primary study goals of our study was to examine the influence of the diet and physical activity patterns of the parent on those of the child. Despite most of our observed relations being non-significant, our findings suggest a positive trend in the relation between a parent's BMI and his/her son's weight status and eating and physical patterns, suggesting that such patterns in parents are highly correlated to patterns in children. Consequently, such patterns can be considered as part of the process whereby a risk of obesity is transmitted to the children, possibly subsequently affecting their weight status. These findings are consistent with those reported in previous studies which found that parents play a pivotal role in the development of their child's food preferences and energy intake [45-47] and also affect the levels of their children's physical activity [48].

Our findings on diet patterns (fruit, vegetable and soda drink consumption) show a trend of unhealthy alimentary 
patterns in both groups, suggesting that parents and children share comparatively few likes and dislikes. There is evidence that parenting practices affect what a child eats and how much; however, few studies to date have used the appropriate experimental designs to provide causal evidence for the indirect effect of parenting on weight status and eating patterns of children. Children are dependent on parents and caregivers for food, which ultimately results in the parent's choices on diet being key determinants of children's eating patterns. These choices include when eating will occur, the type of food eaten and the portions that will be offered, among others. Thus, parents influence children by shaping their eating environment [49].

In those children whose parents were overweight or obese, there was a modestly lower consumption of fruit and vegetables and a higher consumption of soda drinks. These results are consistent with existing data on obese children and adults, which indicate that fruit and vegetable consumption is lower among these individuals than recommended (4 servings per day) for the general population [50, 51]. Moreover, the diet pattern observed in our sample has been documented in previous studies, in which individuals with a low consumption of fruit and vegetables and a higher consumption of high-energy dense foodstuffs, such as soda drinks, are related to a higher risk for obesity [52].

In our sample, the average consumption of soda drinks among children whose parents were considered to be overweight or obese was higher than that among those whose parents were considered to be of normal weight, independent of the high proportion who report consuming these kind of beverages every day, thus increasing the former's risk for developing childhood obesity. A study in a Mexican population found that a higher intake of soda drinks, juices or sugar-sweetened beverages may promote weight gain and obesity by increasing overall energy intake [53]. What is more, subjects consuming three daily serving of soda drinks face a 2.1-fold greater risk of proportional excess body fat than those who consume $<1$ serving a day. A 12-ounce serving of these products provides $150 \mathrm{kcal}$; consequently, if these calories are added to the typical diet without reducing intake from other sources, 1 soda/day could lead to a weight gain of $6.75 \mathrm{~kg}$ in 1 year [54].

Although only a limited number of children were studied, we found that most of the children reported participating in moderate physical activities on a regular basis, watching TV and playing videogames. Our data demonstrate that the total time dedicated to physical activities per week was less than that expended watching TV or playing videogames. The mean time spent watching TV in our children cohort was $4.6 \mathrm{~h} / \mathrm{day}$, which correlates with published results. A study conducted among low- and middleincome children in Mexico City reported that the average time for this specific leisure activity was $4.1 \mathrm{~h} / \mathrm{day}$, with a
$12 \%$ greater risk for obesity for each additional hour of viewing TV programs [55].

The patterns and levels of physical activity described herein are comparable to those reported in other larger studies, in which it was demonstrated that most children are largely sedentary. As in our study, in those studies that measured this variable, the average number of hours spent watching TV was viewed as a marker for sedentary behavior [55-57].

Despite the low proportion of parents who reported participating in regular moderate physical activity at least three times per week, our findings are higher than those reported by the National Survey of the Use of Time in Mexico. This National Survey found that $22.1 \%$ of the population aged $>12$ years participate in some form of physical activity or exercise for $5.5 \mathrm{~h}$ per week and that $81.2 \%$ expend $12.8 \mathrm{~h}$ per week watching TV and $6.9 \mathrm{~h}$ per week using the computer [58]. It should be noted that there always exists the possibility of overestimating physical activity, as has been documented in previous studies among women who were overweight or obese [59-61].

This study is limited by the small sample size. Subjects were recruited in elementary schools by the principal's invitation and by advertisement. It was challenging to recruit parents because most of them stated that they did not have enough time to fill out the questionnaire or they did not want to attend to the planned meetings. Moreover, our measures of the anthropometric variables of the parents are limited to the information reported by the parents themselves. Despite these limitations, there were several strengths to our study. The information derived is valuable as it documents the association between weight status among parents and their children and helps identify groups with a higher risk for obesity based on the parent's weight status. In addition, our measure of diet and physical patterns in parents provides additional evidence for the important role played by parents in influencing the risk of obesity in their children. Our data augment those of previous studies by examining parenting patterns in an older group of children. Previous studies in Mexico on parental influence on children's eating patterns have largely included older children or BP measures.

\section{Conclusion}

The relationship between overweight or obesity in a child and obesity in a respective parent was confirmed in this sample of school-aged Mexican children. Eating patterns of the parents and their children, such as the consumption of soda drinks, fruit and vegetables were also associated.

The association found in our obese children and their obese parents identifies a group for targeted intervention. 
If replicated and confirmed, the findings of our study may help healthcare givers to develop interventions that focus on teaching parents how to increase the physical activity levels of their children, decrease their children's periods of inactivity and improve the diet of their children to include enough fruit and vegetables, all with the aim to prevent the development of overweight or obesity. It is crucial that interventions focus on the home environment, as parenting patterns influence children's dietary and physical habits.

In view of the recognition that diet can make a substantial contribution to variations in health and disease and that making healthy food choices is primordial, further research is needed to evaluate family-based interventions that target the promotion of fruit and vegetable consumption and the practice of physical activity, not just in children but also in their parents, in order to reduce the prevalence of cardiovascular risk factors, such as obesity and hypertension. This kind of intervention is cost-effective because it can influence multiple members of a family.

Acknowledgments A. V. C. is supported by a post-graduate CONACYT scholarship, no. 176239.

Conflict of interest statement No conflict of interest was reported by the authors.

\section{References}

1. Instituto Nacional de Salud Pública. Encuesta Nacional de Nutrición y Salud (ENSANUT), Mexico; 2006.

2. Hossain P, Kawar B, Nahas ME. Obesity and diabetes in the developing world. A growing challenge. $\mathrm{N}$ Engl J Med. 2007;3563:213-5.

3. Haines L, Wan KC, Lynn R, Barrett TG, Shield JPH. Rising incidence of type 2 diabetes in children in the U.K. Diabetes Care. 2007;30:1097-100.

4. Gill TP, Baur LA, Bauman AE, Steinbeck KS, Storlien LH, Fiatarone Singh MA, et al. Childhood obesity in Australia remains a widespread health concern that warrants populationwide prevention programs. Med J Aust. 2009;190:146-8.

5. Falkner B, Sherif K, Michel S, Kushner H. Dietary nutrients and blood pressure in urban minority adolescents at risk for hypertension. Arch Pediatr Adolesc Med. 2000;154:918-22.

6. Whitaker RC, Wright JA, Pepe MS, Seidel KD, Dietz WH. Predicting obesity in young adulthood from childhood and parental obesity. N Engl J Med. 1997;337:869-73.

7. U.S. Surgeon General. The Surgeon General's report on nutrition and health. Washington: U.S. Department of Health and Human Services, Public Health Service; 1988. DHHS Publication No. 88-50210. p. 722.

8. Sallis J, Chen A, Castro C. Child health nutrition and physical activity. IL: Human Kinetics; 1995. p. 179-205.

9. Andersen RE, Crespo CJ, Bartlett SJ, Cheskin LJ, Pratt M. Relationship of physical activity and television watching with body weight and level of fatness among children: results from the Third National Health and Nutrition Examination Survey. JAMA. 1998;279:938-42.
10. Giammattei J, Blix G, Marshak HH, Wollitzer AO, Pettitt DJ. Television watching and soft drink consumption: associations with obesity in 11- to 13-year-old schoolchildren. Arch Pediatr Adolesc Med. 2003;157:882-6.

11. Vartanian LR, Schwartz MB, Brownell KD. Effects of soft drink consumption on nutrition and health: a systematic review and meta-analysis. Am J Public Health. 2007;97:667-75.

12. Malik VS, Schulze MB, Hu FB. Intake of sugar-sweetened beverages and weight gain: a systematic review. Am J Clin Nutr. 2006;84:274-88.

13. Schulze MB, Manson JE, Ludwig DS, Colditz GA, Stampfer MJ, Willett WC, et al. Sugar-sweetened beverages, weight gain, and incidence of type 2 diabetes in young and middle-aged women. JAMA. 2004;292:927-34.

14. Nielsen SJ, Popkin BM. Changes in beverage intake between 1977 and 2001. Am J Prev Med. 2004;27:205-10.

15. Arroyo P, Méndez O. Densidad energética y diversidad de dietas en hogares rurales y urbanos de México e ingreso familiar (19922002). Gac Méd Méx. 2007;4:301-7.

16. Instituto Nacional de Estadística y Geografía (INEGI). El sector alimentario en México 2008.

17. ANAPRAC. La industria de refrescos y aguas carbonatadas en 2005: Anuario estadístico. Mexico DF (Mexico): Asociación Nacional de Productores de Refrescos y Aguas Carbonatadas; 2005.

18. Barquera S, Hernández-Barrera L, Tolentino ML, Espinosa J, Wen S, Rivera J. Energy intake from beverages is increasing among Mexican adolescents and adults. J Nutr. 2008;138:2454-61.

19. Duffey K, Popkin B. Shifts in patterns and consumption of beverages between 1965 and 2002. Obesity. 2007;15:2739-47.

20. Magarey AM, Daniels LA, Boulton TJ, Cockington RA. Predicting obesity in early adulthood from childhood and parental obesity. Int J Obes Relat Metab Disord. 2003;27:505-13.

21. Sekine M, Yamagami T, Hamanishi S. Parental obesity, lifestyle factors and obesity in preschool children: results of the Toyama Birth Cohort study. J Epidemiol. 2002;12:33-9.

22. Lake JK, Power C, Cole TJ. Child to adult body mass index in the 1958 British birth cohort: associations with parental obesity. Arch Dis Child. 1997;77:376-81.

23. Guillaume M, Lapidus L, Beckers F, Lambert A, Bjorntorp P. Familial trends of obesity through three generations: the BelgianLuxembourg child study. Int J Obes Relat Metab Disord. 1995;19:S5-9.

24. Johnson SL, Birch LL. Parents' and children's adiposity and eating styles. Pediatrics. 1994;94:653-61.

25. Ruther NM, Richman CL. The relationship between mothers' eating restraint and their children's attitudes and behaviors. Bull Psychosom Soc. 1993;31:217-20.

26. Coelho R, Sousa S, Laranjo MJ, Monteiro AC, Bragança G, Carreiro H. Overweight and obesity-prevention in the school. Acta Med Port. 2008;21:341-4.

27. Kelder SH, Perry C, Kleep K, Lytle L. Longitudinal tracking of adolescent smoking, physical activity, and food choice behaviors. Am J Public Health. 1994;84(7):1121-6.

28. Lau R, Quadrel M, Hartman KA. Development and change of young adults' preventive health beliefs and behavior: influence from parents and peers. J Health Soc Behav. 1990;31:240-59.

29. Pate R, Small ML, Ross JG, Young JC, Flint KH, Warren CW. School physical education. J Sch Health. 1995;65:312-8.

30. Strauss RS, Knight J. Influence of the home environment on the development of obesity in children. Pediatrics. 1999;103:e85.

31. CONAPO. Algoritmo del índice de marginación: CONAPO. Índices de Marginación 2000. Mexico City: Consejo Nacional de Población. Available at: http://www.conapo.gob.mx/00cifras/ 2000.htm (2001). Accessed 1 Nov 2005. 
32. Lohman TG, Roche AF, Martorell R. Anthropometric standardization reference manual: abridged edition. Champaign: Human Kinetics Books; 1991.

33. Must A, Dallal GE, Dietz WH. Reference data for obesity: 85th and 95th percentiles of body mass index (wt/ht) and triceps skinfold thickness. Am J Clin Nutr. 1991;54:773.

34. Cole TJ, Bellizzi MC, Flegal KM, Dietz WH. Establishing a standard definition for child overweight and obesity worldwide: international survey. Br Med J. 2000;320:1240-3.

35. Paradis G, Lambert M, O'Loughlin J, Lavallée C, Aubin J, Delvin E, et al. Blood pressure and adiposity in children and adolescents. Circulation. 2004;110:1832-8.

36. Stunkard AJ, Albaum JM. The accuracy of self-reported weights. Am J Clin Nutr. 1981;34:1593-9.

37. Stewart AL. The reliability and validity of self-reported weight and height. J Chron Dis. 1982;35:295-309.

38. Hoelscher DM, Day RS, Kelder SH, Ward JL. Reproducibility and validity of the secondary level school-based nutrition monitoring student questionnaire. J Am Diet Assoc. 2003;103:186-94.

39. University of Washington Health Promotion Research Center. Rapid Assessment Physical Activity Scale (RAPA). Available at: http://hmcrc.srph.tau.edu.

40. Sengier A. Multifactorial etiology of obesity: nutritional and central aspects. Rev Med Brux. 2005;26:S211-4.

41. Ortiz-Hernández L, Delgado-Sánchez G, Hernández-Briones A. Cambios en factores relacionados con la transición alimentaria y nutricia en México. Gac Med Mex. 2006;142:181-93.

42. Ogden CL, Troiano RP, Briefel RR, Kuczmarski RJ, Flegal KM, Johnson CL. Prevalence of overweight among preschool children in the United States, 1971 through 1994. Pediatrics. 1997;99:E1-12.

43. Chiolero A, Bovet P, Paradis G, Paccaud F. Has blood pressure increased in children in response to the obesity epidemic? Pediatrics. 2007;119:544-53.

44. Sinha MD, Reid CJD. Evaluation of blood pressure in children. Curr Opin Nephrol Hypertens. 2007;16:577-84.

45. Johannsen DL, Johannsen NM, Speaker BL. Influence of parents' eating behaviors and child feeding practices on children's weight status. Obesity. 2006;14:431-9.

46. Birch LL, Fisher JO. Development of eating behaviors among children and adolescents. Pediatrics. 1998;101:539-49.

47. Wardle J, Guthrie C, Brich L, Plomin R. Food and activity preferences in children of lean and obese parents. Int $\mathrm{J}$ Obes. 2001;25:971-7.

48. Taylor WC, Baranowski T, Sallis JF. Family determinants of childhood physical activity: a social-cognitive model. In:
Dishman RK, editor. Advances in exercise adherence. Champaign: Human Kinetics; 1994. p. 319-42.

49. Ventura A, Birch L. Does parenting affect children's eating and weight status? Int J Behav Nutr Phys Act. 2008;5:15.

50. Casey PH, Szeto K, Lensing S, Bogle M, Weber J. Children in food-insufficient, low income families. Arch Pediatr Adolesc Med. 2001;155:508-14.

51. Matheson DM, Varady J, Varady A, Killen JD. Household food security and nutritional status of Hispanic children in the fifth grade. Am J Clin Nutr. 2002;76:210-7.

52. Ortiz-Hernández L, Acosta-Gutiérrez MN, Núñez-Pérez AE, Peralta-Fonseca N, Ruiz-Gómez Y. En escolares de la Ciudad de México la inseguridad alimentaria se asoció positivamente con el sobrepeso. Rev Inv Clín. 2007;59(1):32-41.

53. Denova-Gutiérrez E, Jiménez-Aguilar A, Halley-Castillo E, Huitrón-Bravo G, Talavera JO, Pineda-Pérez D, et al. Association between sweetened beverage consumption and body mass index, proportion of body fat and body fat distribution in Mexican adolescents. Ann Nutr Metab. 2008;53:245-51.

54. Apovian CM. Sugar-sweetened soft drinks, obesity, and type 2 diabetes. JAMA. 2004;292:978-9.

55. Hernández B, Gortmaker SL, Colditz GA, Peterson KE, Laird NM, Parra-Cabrera S. Association of obesity with physical activity, television programs and other forms of video viewing among children in Mexico City. Int J Obes. 1999;23:845-54.

56. Janz KF, Golden JC, Hansen JR, Mahoney LT. Heart rate monitoring of physical activity in children and adolescents: the Muscatine Study. Pediatrics. 1992;89:256-61.

57. Livingstone MB, Coward WA, Prentice AM, Davies PS, Strain JJ, McKenna PG, et al. Daily energy expenditure in free-living children: comparison of heart-rate monitoring with the doubly labeled water (2H2(18)O) method. Am J Clin Nutr. 1992;56:343-52.

58. Encuesta Nacional sobre Uso de Tiempo. Tabulados básicos definitivos. México: Instituto Nacional de Estadística, Geografía e Informática. INEGI; 2002. p. 2002.

59. Jackicic J, Polley B, Wing R. Accuracy of self-reported exercise and the relationship with weight loss in overweight women. Med Sci Sports Exerc. 1998;30:634-8.

60. Irwin M, Ainsworth B, Conway J. Estimation of energy expenditure from physical activity measures: determinants of accuracy. Obes Res. 2001;9:517-25.

61. Mahabir S, Baer DJ, Giffen C, Clevidence BA, Campbell WS, Taylor PR, et al. Comparison of energy expenditure estimates from 4 physical activity questionnaires with doubly labeled water estimates in postmenopausal women. Am J Clin Nutr. 2006;84:230-6. 